\title{
SUPERAÇÃO DE DORMÊNCIA EM SEMENTES DE FLAMBOYANT (Delonix regia (Bojer ex Hook) Raf.)
}

Claudinei Antonio Bolognez ${ }^{1}$, Simone Pohl ${ }^{2}$, Géri Eduardo Meneguello ${ }^{3}$, Mauro Oswaldo Medeiros ${ }^{4}$; José Liberio do Amaral ${ }^{4}$

${ }^{1}$ Eng. Agr. Mestre em Ciência e Tecnologia de Sementes. Universidade Federal de Pelotas

${ }^{2}$ Doutoranda em Ciência e Tecnologia de Sementes. Universidade Federal de Pelotas

${ }^{3}$ Doutor em Ciência e Tecnologia de Sementes. Bolsista de Produtividade em Pesquisa pelo CNPq, Universidade Federal de Pelotas. Caixa postal 354, Pelotas Brasil. E-mail: geriem@ufpel.edu.br

${ }^{4}$ Prof. da UFMT, Campus Rondonópolis. Departamento de Ciências Biológicas

Recebido em: 08/09/2015 - Aprovado em: 14/11/2015 - Publicado em: 01/12/2015 DOI: http://dx.doi.org/10.18677/Enciclopedia_Biosfera_2015_226

\section{RESUMO}

Delonix regia (flamboyant) é uma espécie arbórea exótica amplamente utilizada no Brasil, de alto valor ornamental por sua exuberância na floração. Sua propagação ocorre por meio de sementes, que apresentam grande variação na viabilidade, em função da impermeabilidade do tegumento à água. Neste sentido, objetivou-se com esse trabalho determinar o melhor método para superação da dormência. As sementes foram submetidas a diferentes tratamentos: Testemunha (1), furo no tegumento (2), escarificação mecânica com lixa oํ 150 (3), imersão em água quente a $100{ }^{\circ} \mathrm{C}$ até temperatura ambiente (4) imersão em água quente a $90^{\circ} \mathrm{C}$ até temperatura ambiente (5). Após, as sementes foram semeadas em casa de vegetação e $B O D$ a $26^{\circ} \mathrm{C}$. Avaliou-se a germinação, em ergência e biometria das sementes. Os melhores métodos de superação das sementes foram furo no tegumento e água a temperatura de $90^{\circ} \mathrm{C}$.

PALAVRAS-CHAVE: Dormência, escarificação mecânica, exótica, superação

\section{OVERCOMING SEED DORMANCY IN FLAMBOYANT (Delonix regia (Bojer ex Hook) Raf.)}

\begin{abstract}
Delonix regia (flamboyant) is exotic tree species widely used in Brazil, highly ornamental plant, for its exuberant flowering. Its propagation is by seeds, which show great variation viability, depending by its impermeable integument to water. In this sense, the objective of this study was to overcome dormancy. Were the seeds submitted to different treatments: Control (1) seed coat the role (2), mechanical scarification with sandpaper 150 (3), imersion in water a $100{ }^{\circ} \mathrm{C}$ to room temperature (4) and imersion in water a $90{ }^{\circ} \mathrm{C}$ to room temperatu re (5). After the seeds were sown in a greenhouse and $B O D$ at $26^{\circ} \mathrm{C}$. We evaluated the germination, emergence
\end{abstract}


and seed biometry. The best methods for overcoming the seeds were, hole in the tegument and water temperature of $90^{\circ} \mathrm{C}$.

KEYWORDS: Dormancy, mechanical scarification, exotic, overcoming

\section{INTRODUÇÃO}

A espécie arbórea Delonix regia (Bojer ex Hook.) Raf., conhecida popularmente como flamboyant, pertencente a família Fabaceae é oriunda de Madagascar, mas amplamente utilizada no Brasil, muito provavelmente em razão do valor ornamental por sua exuberância na floração (SILVA, 2009), além do rápido desenvolvimento vegetativo (ARALDI et al., 2011). A propagação desta espécie é exclusivamente por sementes (LORENZI et al., 2003).

Em sementes de espécies florestais da família Fabaceae, têm sido observadas dificuldades relacionadas à germinação das sementes e a produção de mudas. Diversos autores têm atribuído isso à impermeabilidade do tegumento da semente à água ou ao oxigênio, oferecendo elevada resistência física ao crescimento do embrião (MALAVASI \& MALAVASI, 2004; COSSA et al., 2009) ou pela combinação com outros fatores (BASKIN \& BASKIN, 2004). Esta impermeabilidade causa dormência tegumentar, como pode ser observado nas espécies florestais: Caesalpinia pyramidalis (ALVES et al., 2007); Parkia pendula (PINEDO \& FERRAZ, 2008); Senna multijuga (PIVETA et al., 2010); Bauhinia angulata (SMIDERLE \& LUZ, 2010); Cassia grandis L. (SILVA et al., 2012). As sementes de flamboyiant também apresentam esta característica.

Uma semente é considerada dormente quando não desencadeia o processo germinativo mesmo estando sob condições favoráveis para tal, dentre: semente viável, temperatura adequada, presença de água, substrato, etc, conforme relatado por BASKIN \& BASKIN (2004). A dormência é um importante fator adaptativo e, portanto, um mecanismo de sobrevivência da espécie em determinadas condições, visto que retarda a germinação, distribuindo-a no tempo (POPINIGIS, 1977). No entanto, espécies que possuem sementes dormentes, comumente propiciam uma desuniforme produção de plântulas, dificultando a produção de mudas em viveiros e o planejamento dos plantios (COSTA et al., 2010), muitas vezes gerando a necessidade de serem utilizados tratamentos específicos antes da semeadura para a adequação do estande. Estes tratamentos têm por finalidade uniformizar a germinação da semente e a emergência das plântulas, visando à otimização da produção de mudas (PEREIRA \& FERREIRA, 2010; SILVA et al., 2011).

O desenvolvimento de métodos para escarificação de sementes dormentes torna-se necessário para que seja manifestado o potencial real do lote de sementes tanto no campo como em testes para avaliação da qualidade fisiológica. Assim, o objetivo do presente trabalho foi avaliar a eficiência de diferentes tratamentos prégerminativos utilizados para superar a dormência de sementes de flamboyant (Delonix regia (Bojer ex Hook) Raf.), a fim de aumentar e uniformizar a germinação das sementes.

\section{MATERIAL E MÉTODOS}

O trabalho foi desenvolvido em laboratório e área experimental pertencente ao Departamento de Ciências Biológicas do Instituto de Ciências Exatas e Naturais, Universidade Federal de Mato Grosso, Campus Rondonópolis, MT. A coleta das sementes de flamboyant foi realizada na primeira quinzena de junho, em árvores localizadas na zona urbana de Rondonópolis, MT, as mesmas foram extraídas das 
vagens e beneficiadas manualmente, descartando-se aquelas que estavam quebradas, trincadas ou atacadas por insetos. As sementes que selecionadas foram acondicionadas em recipientes plásticos e armazenadas em local parcialmente escuro.

Após o beneficiamento, foram realizados os seguintes tratamentos para superação da dormência: 1) Testemunha: semente sem qualquer tratamento; 2) Perfuração do tegumento, utilizando-se para isso um prego $12 \times 12$, sendo a perfuração realizada na região central visando não danificar o eixo embrionário; 3) Escarificação mecânica com lixa no 150 para madeira realizada na extremidade oposta a região do hilo, 4) imersão em água a $1^{\circ} 0^{\circ} \mathrm{C}$ deixando esfriar até temperatura ambiente; e, 5) imersão em água $90{ }^{\circ} \mathrm{C}$ de ixando esfriar até temperatura ambiente.

Imediatamente após a aplicação dos tratamentos, foi realizada a avaliação da biometria (peso, largura e comprimento) das sementes individualmente, com o intuito de verificar possíveis alterações nas características físicas das sementes com a aplicação dos tratamentos. Foram avaliadas 50 sementes para cada repetição em cada tratamento.

Posteriormente avaliou-se a eficiência do tratamento de superação de dormência com o teste de germinação, para tanto, as sementes foram semeadas sobre papel germiteste e acondicionadas em câmara (BOD) regulada a ${ }^{2} 6^{\circ} \mathrm{C}$, sendo a percentagem de plântulas normais avaliadas no décimo quinto dia após a semeadura, uma vez que não há parâmetros estabelecidos nas Regras para Análise de Sementes (BRASIL, 2009).

Foi avaliada a emergência, sendo realizada semeadura em recipientes próprios para produção de mudas, contendo como substrato uma mistura de terra e areia lavada, com irrigações diárias mantidas sob telado. Utilizou-se uma semente por embalagem e realizadas avaliações semanais até não haver emergência de novas plântulas. Computou-se a percentagem de emergência e de sementes duras e mortas. A avaliação da presença de sementes mortas e duras se deu por revolvimento do substrato da embalagem e avaliação da semente, 10 dias após o término da emergência.

O delineamento experimental utilizado foi inteiramente casualizado, com cinco tratamentos e quatro repetições, totalizando 20 unidades experimentais cada uma composta por 50 sementes. Os dados obtidos expressos em percentagem foram submetidos à transformação Arco sem (raiz x/100) e posteriormente foram submetidos à análise de variância e as médias comparadas pelo teste de Tukey a $5 \%$, utilizando-se para isso o programa SISVAR (FERREIRA, 2008).

\section{RESULTADOS E DISCUSSÃO}

Os resultados médios da biometria, envolvendo peso, comprimento e largura da semente, associado aos cinco métodos de superação de dormência de sementes de flamboyant encontram-se, na Tabela 1. O tratamento T4 - imersão em água a $100^{\circ} \mathrm{C}$, reduziu o peso das sementes em relação aos demais. A alta temperatura da água pode ter contribuído para a lixiviação de compostos da semente, reduzindo com isso o peso. Comprimento e largura não foram afetados pelos tratamentos de superação de dormência. 
TABELA 1. Valores médios de peso, comprimento e largura da semente de flamboyant, associada aos diferentes métodos de tratamentos para superação de dormência: T1) Semente sem tratamento para superação de dormência; T2) Perfuração do tegumento; T3) Escarificação mecânica com lixa no 150; T4) imersão em água a $100{ }^{\circ} \mathrm{C}$ e, T5) imersão em água $90{ }^{\circ} \mathrm{C}$.

\begin{tabular}{|c|c|c|c|c|c|c|}
\hline \multirow{2}{*}{ Avaliações } & \multicolumn{5}{|c|}{ Métodos de Superação de Dormência } & \multirow{2}{*}{$\mathrm{Cv}(\%)$} \\
\hline & T1 & T2 & T3 & T4 & T5 & \\
\hline Peso $(\mathrm{g})$ & $0,46 \mathrm{a}$ & $0,45 \mathrm{a}$ & $0,45 \mathrm{a}$ & $0,44 \mathrm{~b}$ & $0,47 \mathrm{a}$ & 26,95 \\
\hline Comprimento (mm) & $20,1 \mathrm{a}$ & $19,9 \mathrm{a}$ & 20,9 a & 19,9 a & $20,5 a$ & 6,65 \\
\hline Largura $(\mathrm{mm})$ & $6,7 \mathrm{a}$ & $6,6 \mathrm{a}$ & $6,6 \mathrm{a}$ & $6,7 \mathrm{a}$ & $6,7 \mathrm{a}$ & 7,54 \\
\hline
\end{tabular}

De acordo com CARVALHO \& NAKAGAWA (1983), as sementes de maior tamanho, geralmente, foram melhor nutridas durante o desenvolvimento, possuindo embriões bem formados e com maior quantidade de substâncias de reserva, sendo, consequentemente, as mais vigorosas. Dados obtidos por CARVALHO (1972), com sementes de amendoim, comprovam que sementes de maior tamanho apresentaram maiores percentagens de germinação e vigor das plântulas formadas relativamente às menores. E de acordo com CARVALHO \& NAKAGAWA (2000), sementes de maior tamanho originam plântulas mais vigorosas que, em condições variáveis de campo, podem resultar em "stands" diferentes em favor das maiores.

Comparando-se os dados médios de germinação das sementes escarificadas e não escarificadas verificaram-se diferenças significativas entre os tratamentos (Tabela 2), evidenciando-se a eficiência da escarificação e a necessidade de aplicação de métodos de superação em sementes de flamboyant visando a produção de mudas. Quando não aplicados métodos de superação de dormência apenas um por cento das sementes germinaram. Foi mais notória para a semente submetida à água aquecida a $100^{\circ} \mathrm{C}$ com a imersão das sementes (4), sem diferir significativamente dos métodos escarificação mecânica com lixa no 150 para madeira (3), água aquecida a ponto de fervura com a imersão das sementes e aquecimento da água até $90^{\circ} \mathrm{C}$ e posterior imersão da s sementes deixando esfriar até temperatura ambiente (5).

Segundo YAP \& WONG (1983), a ação de altas temperaturas exerce um papel ecológico importante na superação da dormência das sementes de algumas espécies florestais, promovendo fissuras no tegumento, facilitando a absorção de água e gases, desencadeando o processo germinativo e, consequentemente, favorecendo o estabelecimento da regeneração natural destas espécies.

TABELA 2. Valores médios de germinação de sementes de flamboyant (Delonix regia Raf.) em BOD a $26^{\circ}$ C, associada a métodos de superação: T1) Semente sem tratamento para superação de dormência; T2) Perfuração do tegumento; T3) Escarificação mecânica com lixa oㅡ 150; T4) imersão em água a $1^{\circ 00} \mathrm{C}$ e, T5) imersão em água $90^{\circ} \mathrm{C}$.

\begin{tabular}{lc}
\hline Tratamentos & Germinação $(\%)$ \\
\hline T1 & $1 \mathrm{c}$ \\
T2 & $67 \mathrm{~b}$ \\
T3 & $77 \mathrm{ab}$ \\
T4 & $80 \mathrm{a}$ \\
T5 & $77 \mathrm{ab}$ \\
\hline Cv $(\%)$ & 11,62 \\
\hline
\end{tabular}

Médias seguidas da mesma letra minúscula na coluna não diferem entre si, pelo teste de Tukey, a $5 \%$ de probabilidade. 
Os resultados médios de porcentagem total de emergência, sementes mortas e duras de flamboyant, após os tratamentos pré-germinativos, encontram-se na Tabela 3. No tratamento um, testemunha, sem superação de dormência, a emergência foi de $27 \%$, muito superior que o observado no teste de germinação realizado em BOD, onde apenas um por cento das sementes germinou. Este comportamento é esperado, pois no substrato utilizado, formado pela mistura de terra e areia, há ácidos orgânicos e outros compostos químicos que atuam na degradação do tegumento da semente, tornando-o permeável a água, desencadeando com isso o processo germinativo. Apesar disso a emergência foi inferior a todos os demais tratamentos de superação de dormência.

TABELA 3. Emergência (\%) de sementes flamboyant, a partir de sementes submetidas aos métodos de tratamento: T1) Semente sem tratamento para superação de dormência; T2) Perfuração do tegumento; T3) Escarificação mecânica com lixa nำ 150; T4) imersão em água a $100^{\circ} \mathrm{C}$ e, T5) imersão em água $90^{\circ} \mathrm{C}$.

\begin{tabular}{|c|c|c|c|c|c|c|}
\hline \multirow{2}{*}{ Avaliações } & \multicolumn{5}{|c|}{ Métodos de Superação de Dormência } & \multirow{2}{*}{$\begin{array}{l}\text { CV } \\
(\%)\end{array}$} \\
\hline & T1 & T2 & T3 & T4 & T5 & \\
\hline Emergência (\%) & $27 \mathrm{~d}$ & $63 \mathrm{a}$ & $37 \mathrm{c}$ & $43 \mathrm{~b}$ & $63 \mathrm{a}$ & 12,5 \\
\hline Sementes mortas (\%) & $3 \mathrm{~b}$ & $0 \mathrm{c}$ & $3 \mathrm{~b}$ & $0 \mathrm{c}$ & $7 \mathrm{a}$ & 17,6 \\
\hline Sementes duras (\%) & $70 \mathrm{a}$ & $37 \mathrm{c}$ & $60 \mathrm{~b}$ & $57 \mathrm{~b}$ & $30 \mathrm{c}$ & 9,38 \\
\hline
\end{tabular}

Médias seguidas da mesma letra minúscula na linha não diferem entre si, pelo teste de Tukey, a $5 \%$ de probabilidade.

Pode-se observar que houve diferença, entre as sementes de flamboyant submetidas aos métodos de superação e associadas às percentagens de emergência, sementes mortas e duras (Tabela 3). Dessa forma, o método que obteve o melhor resultado foi com as sementes tratadas com um furo no tegumento (2) e aquecimento da água até $90^{\circ} \mathrm{C}$ e posterior imersão das sementes deixando esfriar até temperatura ambiente (5), germinação de 63\%, sem diferir entre si. Considerando eficiência similar entre os métodos o viveirista poderá adotar o que for mais prático considerando a sua realidade.

Segundo HERMANSEN et al. (2000), entre os métodos utilizados para superação da dormência tegumentar, a escarificação mecânica é uma técnica freqüentemente utilizada e constitui a opção mais prática e segura para pequenos agricultores, por ser um método simples e de baixo custo. No entanto, deve ser efetuada com cuidado para evitar que a escarificação excessiva possa causar danos ao tegumento e diminuir as taxas de germinação (MCDONALD \& COPELAND 1997).

Comparando com a testemunha, observou-se a eficiência desses métodos, uma vez que foi superada a impermeabilidade do tegumento das sementes, sem ocorrer danos consideráveis. Em trabalho semelhante, COSSA et al. (2009), relatam que o tratamento com imersão das sementes em água à temperatura de $80 \stackrel{\circ}{\circ}$ por 24 horas mostrou-se eficiente para superação de dormência de sementes de flamboyant, verificando-se $51 \%$ de plântulas emergidas e que a temperatura de 100 ○C reduziu a emergência das plântulas, além de deteriorar maior número de sementes. Segundo LIMA et al. (2013), ao trabalharem com sementes de flamboyant, obtiveram como melhor resultado a escarificação mecânica e água quente a $80^{\circ} \mathrm{C}$. 


\section{CONCLUSÕES}

A imersão das sementes de flamboyant (D. regia) em água aquecida a $90^{\circ} \mathrm{C}$, deixando-as esfriar até temperatura ambiente e a perfuração do tegumento caracterizam-se como métodos eficientes para a superação de dormência.

Os métodos de superação de dormência de sementes de flamboyant $(D$. regia) testados não alteram o peso, largura e comprimento das sementes.

\section{REFERÊNCIAS}

ALVES, E. U.; CARDOSO, E. A.; BRUNO, R. L. A.; ALVES, A. U.; ALVES, A. U. GALINDO, E. A.; BRAGA JUNIOR, J. M. Superação da dormência de sementes de Caesalpinia pyramidalis Tul. Revista Árvore, Viçosa, v. 31, n. 3, p. 405-415, 2007.

ARALDI, C. B.; PURETZ, B. O.; MARQUES, E. F.; POLASSO, M. B.; BRUN, E. J.; BRUN, F. G. K. Emergência e desenvolvimento inicial de plantas de Delonix regia de acordo com o substrato. In: CONGRESSO DE CIÊNCIA E TECNOLOGIA DA UTFPR, 1., 2011, Dois Vizinhos. Resumos... Dois Vizinhos: UTFPR, p. 204-206. 2011.

BASKIN, J.M.; BASKIN, C.C. A classification system for seed dormancy. Seed Science Research v.14, p.1-16, 2004.

BRASIL. Ministério da Agricultura, Pecuária e Abastecimento. Regras para análise de sementes. Brasília: Mapa/ACS, 395 p. 2009.

CARVALHO, N. M. Efeitos do tamanho sobre o comportamento da semente de amendoim (Arachis hypogaea L.). Ciência e cultura, São Paulo, v. 24, n. 1, p. 6469, 1972.

CARVALHO, N. M.; NAKAGAWA, J. Sementes: Ciência, tecnologia e produção. 4.ed. Jaboticabal: FUNEP, p588, 2000.

CARVALHO, N.M.; NAKAGAWA, J. Sementes: Ciência, tecnologia e produção. 2.ed. Campinas: Fundação Cargill, p429, 1983.

COSSA, A.; SORACE, A. da F.; LIMA, B. de; OSIPI, A. F.; MANTOAN, P.; POLÔNIO, D.; JANANI, K. Aspectos da germinação de sementes de Delonix regia (Bojer ex Hook.) Raf. Resumos do VI CBA e II CLAA. Revista Brasileira de Agroecologia, v. 4, n. 2, 2009.

COSTA, P. A.; LIMA, A. L. S.; ZANELLA, F.; FREITAS, H. Quebra de dormência em sementes de Adenanthera pavonina L. Pesquisa Agropecuária Tropical, Goiânia, v. 40 , n. 1 , p. $83-88,2010$.

FERREIRA, D.F. SISVAR: Um programa para análises e ensino de estatística. Revista Científica Symposium, Lavras, v. 6, n. 2, p. 36-41, 2008. 
HERMANSEN, L. A.; DURYEA, M. L.; WEST, S. H.; WHITE, T. L.; MALAVASI, M. M. Pretreatments to overcome seed coat dormancy in Dimorphandra mollis. Seed Science \& Technology, v. 28, n. 1, p. 581-595, 2000.

LIMA, J.S.; CHAVES, A.P.; MEDEIROS, M.A.; RODRIGUES, G.S.O.; BENEDITO, C.P. Métodos de superação de dormência em sementes de flamboyant (Delonix regia). Revista Verde. v. 8, n. 1, p. 104-109, 2013.

LORENZI, H.; SOUZA, H.M.DE; TORRES, M.A.V.; BACHER, L.B. Árvores exóticas no Brasil. Odessa: Instituto Plantarum. 384 p., 2003.

MALAVASI, U. C.; MALAVASI, M. M. Dormancy breaking and germination of Enterolobium contortisiliquum (Vell.) Morong seed. Brazilian Archives of Biology and Technology, v.47, p.851-854, 2004.

MCDONALD, M.B.; COPELAND, L.O. Seed production: principles and practices. New Jersey: Chapmam \& Hall, 749 p. 1997.

PEREIRA, S. A.; FERREIRA, S. A. N. Superação da dormência em sementes de visgueiro-do-igapó (Parkia discolor). Revista Acta Amazonica, v. 40, n. 1, p. 151156, 2010.

PINEDO, G. J. V.; FERRAZ, I. D. K. Hidrocondicionamento de Parkia pendula [Benth ex Walp]: sementes com dormência física de árvore da Amazônia. Revista Árvore, Viçosa, v. 32, n. 1, p. 39- 49, 2008.

PIVETA,G.; MENEZES, V.O.; PEDROSO,D.C.; MUNIZ, M.F.B.; BLUME, E.; WIELEWICKI, A.B. Superação de dormência na qualidade de sementes e mudas: influencia na produção de Senna multijuga (L.C.Rich) Irwin \& Barneby. Revista Acta Amazônica, v. 40, n 2, p.281-288, 2010.

POPINIGIS, F. Fisiologia de sementes. Brasília, AGIPLAN, p289,1977.

SILVA, A. G.; COSTA, L. G.; GOMES, D. R.; BROCCO, V. F. Testes para quebra de dormência de sementes de Cassia grandis $L$. e, morfologia de sementes, frutos e plântulas. Enciclopédia Biosfera, Goiânia, v. 8, n. 14, p. 907-912, 2012.

SILVA, C. da. Distribuição espacial do flamboyant, espécie exótica da Mata Atlântica, no Campus I da Universidade Federal da Paraíba. Universidade Federal da Paraíba - Centro de Ciências Exatas e da Natureza. Curso de Graduação em Geografia, 2009.

SILVA, P. E. M.; SANTIAGO, E. F.; DALOSO, D. M.; SILVA, E. M.; SILVA, J. O. Quebra de dormência em sementes de Sesbania virgata (Cav.) Pers. Idesia, Arica, v. 29 , n. 2, p. 39-45, 2011.

SMIDERLE, O.J.; LUZ, F.J.F. Superação da dormência em sementes de pata-devaca (Bauhinia angulata Vell). Revista Agro@mbiente, v. 4, n. 2, p. 80-85, 2010. 
YAP, S.K. ; WONG, S.M. Seed biology of Acacia mangium, Albizia falcataria, Eucalyptus sp., Gmelina arborea, Malsopsis eminiis, Pinus caribaea and Tectonia grandis. The Malaysian Forester, v.6, n.1, p.16-45, 1983. 